\title{
anatomy
}

\section{A morphometric study of the odontoid process using three-dimensional computed tomography (3-D CT) reconstruction}

\author{
Ece Alim ${ }^{1}$ (D), Kerem Atalar ${ }^{2}$ (D), İsmail Nadir Gülekon ${ }^{1}$ (iD \\ ${ }^{1}$ Department of Anatomy, School of Medicine, Gazi University, Ankara, Turkey \\ ${ }^{2}$ Department of Anatomy, School of Medicine, Biilent Ecevit University, Zonguldak, Turkey
}

\begin{abstract}
Objectives: The aim of this study was to evaluate the morphometric parameters of the odontoid process using 3-dimensional (3D) reconstruction of computed tomography (CT) images and investigate the applicability of using one or two screws for fixing odontoid process fractures.

Methods: CT images of 100 patients (55 males, 45 females) were transferred to the OsiriX program in DICOM format and converted into three dimensional images using the 3D volume rendering feature. Male and female groups were divided into 8-30, 31-50 and over 50 age groups and features of the odontoid process were measured.

Results: In the coronal plane, the minimum external transverse length of the odontoid process (OPmin) was highest in males over 50 year of age with a value of $11.3 \mathrm{~mm}$. In the sagittal plane, the combination of anterior-posterior length of the odontoid process and vertebral body (OPAP) was highest in the males over $50(14.5 \mathrm{~mm})$. The length of the line taken from the anteriorinferior corner of the vertebral body to the top of odontoid process (LAIT) was measured the highest measured as $45.2 \mathrm{~mm}$ in males over 50. These measurements were higher in males than females.

Conclusion: The results of this study showed that it is possible to use a single $4.5 \mathrm{~mm}$ or $3.5 \mathrm{~mm}$ cannulated screw in the Turkish population. The application of two $3.5 \mathrm{~mm}$ screws was found to be appropriate in $76 \%$ of males and $62 \%$ of females.
\end{abstract}

Keywords: 3-dimensional reconstruction method; axis; CT; fracture; odontoid process

Anatomy 2019;13(2):80-86 @2019 Turkish Society of Anatomy and Clinical Anatomy (TSACA)

\section{Introduction}

In the adult human, the vertebral column is composed of 33 vertebrae and is divided into five regions. There are 7 cervical, 12 thoracic, 5 lumbar, 5 sacral and 4 coccygeal vertebrae. ${ }^{[1]}$ These different types of vertebrae are arranged on top of each other, supported by an intervertebral disc, with fibrocartilaginous structure and muscles, extending from the skull to the pelvis and forming axial support to the body. ${ }^{[2,3]}$ They undertake important functions such as protection of the vertebral column, spinal cord, and spinal nerves, carrying and transferring body weight, and creating a flexible axle for head and body movements. ${ }^{[4-6]}$ The most different part of the vertebral column is the cervical. The neck is a cylindrical structure that contains vital organs, connects the head and the body together. ${ }^{[7]}$

The odontoid process (dens axis) is a characteristic anatomical element of $\mathrm{C} 2$ vertebrae, playing an important role in $\mathrm{C} 1-\mathrm{C} 2$ vertebrae functions. Phylogenetically, the odontoid process extends up to the upper half of the trunk and consists of four different parts; the tip, body, neck and base. ${ }^{[8]}$ It is a critical component of the craniocervical junction. Therefore, detailed information of the embryology and anatomical variations by clinicians performing diagnosis, treatment, and operation in this region is necessary. ${ }^{[9]}$

Specifically, odontoid process fractures are frequently encountered and treated conservatively or surgically. 
Surgical treatment is performed by using posterior C1-C2 fusion or anterior osteosynthesis using plates and screws or by fixing the odontoid process fracture with one or two screws. ${ }^{[8]}$ Each screw application has its own indications, but mainly depends on the anatomical features of the odontoid process and the type of fracture..$^{[10]}$ Odontoid process fractures are approximately 10-14\% of all cervical spine fractures. ${ }^{[1]]}$ Therefore, understanding of the unique anatomy and architecture of the odontoid process, creation of a specific, pattern of fractures, mechanism of fractures and understanding of the biomechanics of the odontoid process is important for treatment and prognosis. The anatomic structure must be known in advance, especially for anterior and posterior surgical stabilization. ${ }^{[12,13]}$

Studies on the odontoid process morphology in the Turkish population are limited. In this study, the anatomical features of the odontoid process and the three-dimensional reconstruction technique, which has been proven to be accurate in various applications for spinal surgery, have been measured on computed tomography (CT) images. We believe that our study is clinically important for the calculation of axial diameters and for the feasibility of screwing techniques that can be used in the treatment of fractures due to trauma, has a unique value at this point.

\section{Materials and Methods}

This study was performed at the Department of Anatomy of Gazi University School of Medicine and Department of Anatomy of Bülent Ecevit University School of Medicine. Ethical approval was granted by the Local Ethics Committee of Gazi University Faculty of Medicine (approval number: 09.04.2018, 263). CT images of patients who underwent cervical region examination for any reason in the Department of Radiology of Gazi University Hospital were evaluated retrospectively. CT images of patients with pathology or operation history in the cervical region and who could not obtain quantitative data from medical imaging were discluded from the study. Measurements were performed on CT images of 100 patients (55 males, 45 females).

A total of 100 CT images selected for evaluation were transferred to the OsiriX open-source imaging software (free download from http://www.osirix-viewer.com/) in DICOM format. With the $3 \mathrm{D}$ volume rendering feature of the OsiriX program, images were converted to three dimensions. Density adjustments were made to best observe the bone tissue. The three-dimensional image obtained was evaluated from the proximal to the distal to the sagittal and coronal surface sections. The length, volume, and angles measured are shown in Table 1. The images showing the measurements performed on the CT images are shown in Figure 1.

Statistical analysis of the obtained measurement results performed with IBM SPSS Statistics for Windows (Version 19, Armonk, NY, USA). ShapiroWilk test was used to determine the consistency of continuous variables to normal distribution. The normality of each parameter was evaluated using Student's t-test and the normal distribution with Mann-Whitney $U$ test. The mean value of standard deviation (SD) was evaluated by the t-test and the value of the test with the minimum, maximum and median values were evaluated with Mann-Whitney U test (Table 2).

The study group was divided into three age groups: $18-30,31-50$ and over 50. The median (min-max) values of each age group according to the parameters are given in Table 3. Kruskal-Wallis test was used to test the significance of the differences between the averages of

Table 1

Measurements of the odontoid process.

\begin{tabular}{ll}
\hline OPmin & In the coronal plane, the minimum external transverse length of the odontoid process $(\mathrm{mm})$ \\
\hline OPmax & In the coronal plane, the maximum transverse length of the combination of the vertebral body and odontoid process (mm) \\
\hline OPAP & In the sagittal plane, the combination of the anterior-posterior length of the odontoid process and vertebral body $(\mathrm{mm})$ \\
\hline OPL & In the coronal plane, the length between of the apex of the odontoid process and the combination of the odontoid process-vertebral body ( $\mathrm{mm})$ \\
\hline VOL & Odontoid process volume $\left(\mathrm{mm}^{3}\right)$ \\
\hline OPangle & $\begin{array}{l}\text { The angle between the line starting from the anterior-superior corner of the vertebral body, ending at the anterior-inferior the corner of the vertebral body } \\
\text { and the line between the anterior-inferior corner of the vertebral body to the top of the odontoid process }\left(^{\circ}\right)\end{array}$ \\
\hline LAIT & \begin{tabular}{l} 
The length of the line taken from the anterior-inferior corner of the vertebral body to the top of the odontoid process $(\mathrm{mm})$ \\
\hline
\end{tabular}
\end{tabular}



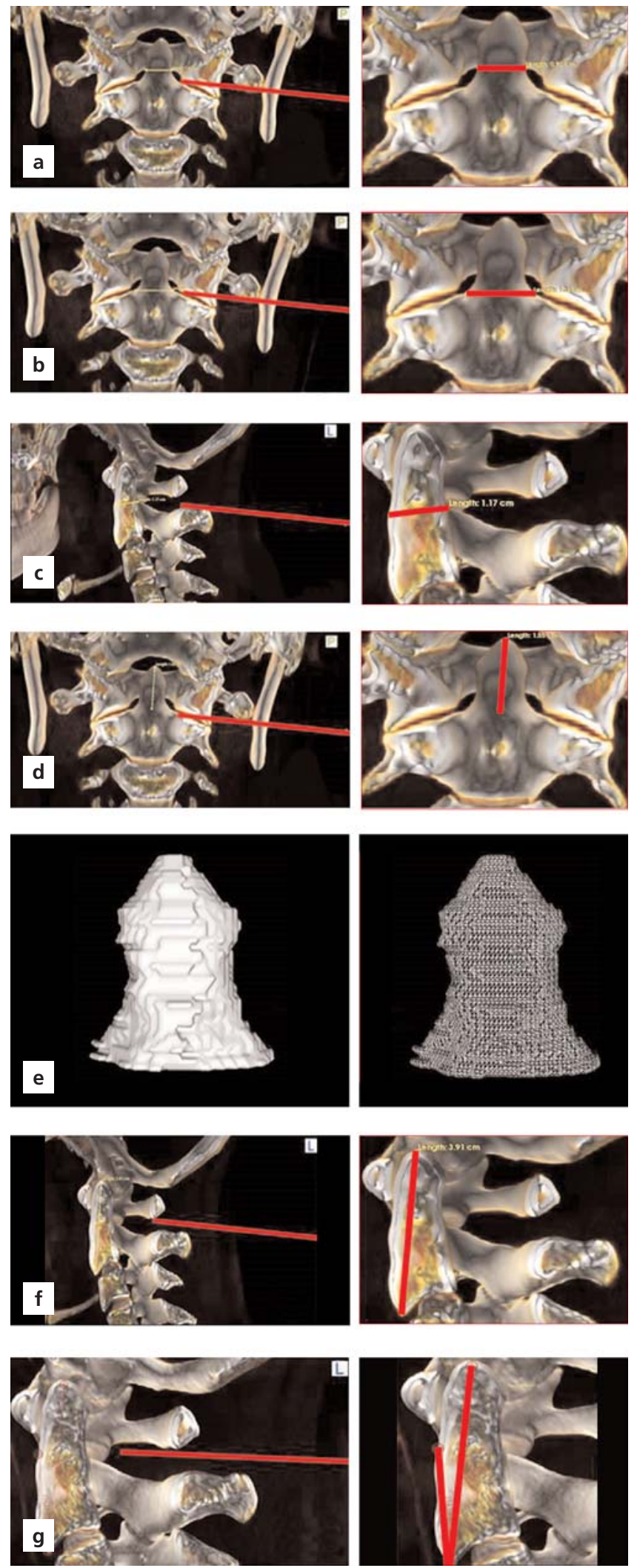

Figure 1. OPmin (a), OPmax (b), OPAP (c), OPL (d), VOL (e), OPangle (f) and LAIT (g). [Color figure can be viewed in the online issue, which is available at www.anatomy.org.tr] those who did not show normal distribution among the three age groups, and the one-way analysis of variance (ANOVA) test was used for those with a normal distribution. In all statistical analyses, comparisons with p-values below 0.05 were considered statistically significant.

\section{Results}

In this study, data of the anatomical morphology of the odontoid process were measured. From these data, values other than OPangle were higher in males than in females (Table 4, Figure 2).

Mean values of OPmin in females with respect to age groups were $8.79 \mathrm{~mm}(7.4-9.9 \mathrm{~mm})$ in the $18-30$ year old, $9.26 \mathrm{~mm}(7.6-10.5 \mathrm{~mm})$ in the $31-50$ year old groups, and $9.24 \mathrm{~mm}(6.9-10.7 \mathrm{~mm})$ in the group over 50 .

Mean values of OPmax were $12.31 \mathrm{~mm}(10.3-14$ $\mathrm{mm}$ ) in the $18-30$ year old male group and $12.86 \mathrm{~mm}$ (11.3-14.6 mm) in males over 50. Values of both groups were the highest in males. However, mean OPmax was $12.4 \mathrm{~mm}(9.3-14.5 \mathrm{~mm})$, higher in females in the 31-50 year old group compared to the same age group of males.

According to age groups, OPAP showed higher mean values in males compared to females; $11.78 \mathrm{~mm}(9.9-13.3$ $\mathrm{mm})$ in the $18-30$ year old, $11.88 \mathrm{~mm}(10.1-13.2 \mathrm{~mm})$ in the $31-50$ year old group, and $12.17 \mathrm{~mm}(9.6-14.5 \mathrm{~mm})$ in the group over 50 .

OPL values, in males according to age groups were; $15.56 \mathrm{~mm}(10.6-18.8 \mathrm{~mm})$ in the $18-30$ year old group; $15.9 \mathrm{~mm}(13.2-19.7 \mathrm{~mm})$ in the $31-50$ year old group; $16.47 \mathrm{~mm}(13.2-21.3 \mathrm{~mm})$ in the group over 50 . These measurements were higher than those in females. VOL values were higher in males than in females. Mean values of OPangle were $12.52^{\circ}\left(9.02-16.5^{\circ}\right)$ in $18-30$ year old females; $12.85^{\circ}\left(8.4-19.08^{\circ}\right)$ in the female group over 50 and the highest mean value was measured as $12.67^{\circ}$ $\left(9.12-20.85^{\circ}\right)$ in the $31-50$ year old male group.

LAIT showed higher mean values in males than females and was $38.73 \mathrm{~mm}(30.5-45.8 \mathrm{~mm})$ in the $18-30$ year old group, between $38.82 \mathrm{~mm} \mathrm{(33.2-45.4)}$ in the $31-50$ year old, and $39.49 \mathrm{~mm}(33.7-45.2 \mathrm{~mm})$ in the over 50 groups.

\section{Discussion}

The number of high or medium quality anatomical studies to guide the surgical treatment of non-stable Type II odontoid process fractures is few. A combination of expert opinion, patient and surgeon selection, and the best available information should be made when appropriate treatment is being performed. Knowing the length 
Table 2

Comparison of the odontoid process measurements by gender.

\begin{tabular}{|c|c|c|c|c|c|}
\hline & Gender & $\mathrm{n}$ & Mean \pm SD & t-test value & p-value \\
\hline \multirow[t]{3}{*}{ OPL } & Female & 45 & $14.7 \pm 1.4$ & & \\
\hline & Male & 55 & $15.8 \pm 1.8$ & 3.097 & 0.003 \\
\hline & Total & 100 & $15.3 \pm 1.7$ & & \\
\hline \multirow[t]{3}{*}{ OPmin } & Female & 45 & $9.1 \pm 0.9$ & & \\
\hline & Male & 55 & $9.5 \pm 0.7$ & -2.558 & 0.012 \\
\hline & Total & 100 & $9.3 \pm 0.8$ & & \\
\hline \multirow[t]{3}{*}{ OPmax } & Female & 45 & $12 \pm 1.4$ & & \\
\hline & Male & 55 & $12.4 \pm 1.1$ & -1.351 & 0.180 \\
\hline & Total & 100 & $12.2 \pm 1.3$ & & \\
\hline \multirow[t]{4}{*}{ LAIT } & Female & 45 & $36.5 \pm 2.3$ & & \\
\hline & Male & 55 & $38.9 \pm 2.8$ & -4.441 & 0.001 \\
\hline & Total & 100 & $37.9 \pm 2.9$ & & \\
\hline & Gender & n & Median (min-max) & Mann-Whitney U test value & p-value \\
\hline \multirow[t]{3}{*}{ OPAP } & Female & 45 & $11.4(9.5-14.1)$ & & \\
\hline & Male & 55 & $11.9(1.2-14.5)$ & 756.5 & 0.001 \\
\hline & Total & 100 & $11.7(1.2-14.5)$ & & \\
\hline \multirow[t]{3}{*}{ OPangle } & Female & 45 & $11.7(8.4-19.2)$ & & \\
\hline & Male & 55 & $10.7(7.5-20.9)$ & 1035.5 & 0.162 \\
\hline & Total & 100 & $11.6(7.5-20.9)$ & & \\
\hline \multirow[t]{3}{*}{ VOL } & Female & 45 & $11.2(8.3-20.4)$ & & \\
\hline & Male & 55 & $13.6(8.3-19.8)$ & 633.5 & $<0.001$ \\
\hline & Total & 100 & $12.9(8.3-20.4)$ & & \\
\hline
\end{tabular}

and diameter of the odontoid process size is crucial in order to decide the application of one or two screws. When deciding to perform an anterior or posterior surgical procedure, the fracture line, bone quality of the patient and the parameters related to technical factors should be thoroughly mastered.

Knowing the length and diameter due to the diversity of the odontoid process size is very important in order to decide on the application of one or two screws. The decision to perform anterior or posterior surgery is based on the fracture line, the patient's bone quality and the technical factors. ${ }^{[14]}$

The first studies have shown that the two-screw technique will provide superior mechanical stability. ${ }^{[15]}$ Some odontoid process diameters may not be large enough to accommodate two $3.5 \mathrm{~mm}$ cortical screws. The placement of two screws in these patients is difficult and even risky. Although this technical difficulty was not emphasized in the initial reports, there was a need to perform quantitative morphometric studies on the fixation of the odontoid process, possibly due to the use of different techniques applied in different regions. ${ }^{[16,17]}$ There are studies indicating that the anteroposterior diameter of the bread is significantly larger than the transverse diameter. ${ }^{[17,18]}$ In this study, we also observed this result in the groups of females and males (OPAP>OPmin). The transverse diameter of the odontoid process is the smallest diameter and is critical for placing two screws when placed side by side in the coronal or transverse plane. ${ }^{[16]}$ The minimum transverse diameter (OPmin) of the odontoid process to accommodate two $3.5 \mathrm{~mm}$ cortical screws should be $9 \mathrm{~mm}$ and $8 \mathrm{~mm}$, if no guide is used. ${ }^{[16]} \mathrm{A}$ critical value of $9 \mathrm{~mm}$ for OPmin is required for the inner cortex of the odontoid process to be left with at least 0.5 $\mathrm{mm}$ cortical bone outside the screws and a gap of at least $1 \mathrm{~mm}$ between the implants. However, if the inner cortex is not blocked, the intramedullary diameter should be at least $8 \mathrm{~mm}$ to accommodate the two screws, considering that the two implants extend to the lateral cortex, with a distance of $1 \mathrm{~mm}$ between them. ${ }^{[16]}$ However, in some 
Table 3

Comparison by age groups.

\begin{tabular}{|c|c|c|c|c|c|}
\hline & Age (years) & $\mathrm{n}$ & Median (min-max) & Kruskal- Wallis test value & p-value \\
\hline \multirow[t]{4}{*}{ OPL } & $18-30$ & 36 & $15.1(10.6-18.8)$ & \multirow{4}{*}{3.419} & \multirow{4}{*}{0.181} \\
\hline & $31-50$ & 39 & $15(11.2-19.7)$ & & \\
\hline & $>50$ & 25 & $15.7(13.2-19.2)$ & & \\
\hline & Total & 100 & $15.1(10.6-19.7)$ & & \\
\hline \multirow[t]{4}{*}{ OPmin } & $18-30$ & 36 & $9.3(7.4-10.6)$ & \multirow{4}{*}{6.158} & \multirow{4}{*}{0.046} \\
\hline & $31-50$ & 39 & $9.3(7.6-10.7)$ & & \\
\hline & $>50$ & 25 & $9.6(6.9-10.8)$ & & \\
\hline & Total & 100 & $9.3(6.9-10.8)$ & & \\
\hline \multirow[t]{4}{*}{ OPAP } & $18-30$ & 36 & $11.4(9.7-13.3)$ & \multirow{4}{*}{3.348} & \multirow{4}{*}{0.188} \\
\hline & $31-50$ & 39 & $11.8(1.2-14.1)$ & & \\
\hline & $>50$ & 25 & $11.8(9.5-14.5)$ & & \\
\hline & Total & 100 & $11.7(1.2-14.5)$ & & \\
\hline \multirow[t]{4}{*}{ OPangle } & $18-30$ & 36 & $11.6(7.5-17.3)$ & \multirow{4}{*}{0.681} & \multirow{4}{*}{0.681} \\
\hline & $31-50$ & 39 & $11.5(8.8-20.9)$ & & \\
\hline & $>50$ & 25 & $11.6(8.1-19.1)$ & & \\
\hline & Total & 100 & $11.6(7.5-20.9)$ & & \\
\hline \multirow[t]{5}{*}{ VOL } & $18-30$ & 36 & $12.6(8.3-19)$ & \multirow{4}{*}{0.013} & \multirow{4}{*}{0.994} \\
\hline & $31-50$ & 39 & $13.3(8.3-20.4)$ & & \\
\hline & $>50$ & 25 & $13(9-19.8)$ & & \\
\hline & Total & 100 & $12.9(8.3-20.4)$ & & \\
\hline & Age (years) & $\mathrm{n}$ & Median (min-max) & One-way ANOVA test value & $p$-value \\
\hline \multirow[t]{4}{*}{ OPmax } & $18-30$ & 36 & $12.1 \pm 1.3$ & \multirow{4}{*}{0.261} & \multirow{4}{*}{0.771} \\
\hline & $31-50$ & 39 & $12.2 \pm 1.3$ & & \\
\hline & $>50$ & 25 & $12.3 \pm 1.3$ & & \\
\hline & Total & 100 & 12. \pm 1.3 & & \\
\hline \multirow[t]{4}{*}{ LAIT } & $18-30$ & 36 & $37.5 \pm 3$ & \multirow{4}{*}{0.611} & \multirow{4}{*}{0.545} \\
\hline & $31-50$ & 39 & $37.7 \pm 2.7$ & & \\
\hline & $>50$ & 25 & $38.3 \pm 2.9$ & & \\
\hline & Total & 100 & $37.8 \pm 2.9$ & & \\
\hline
\end{tabular}

studies, less than $9 \mathrm{~mm}$ of external anteroposterior diameter was determined. ${ }^{[16,17]}$

When the information given above and OPmin we have obtained are evaluated together; $62 \%$ of females, $76 \%$ of males and $70 \%$ of the total group had a suitable odontoid process for two $3.5 \mathrm{~mm}$ cortical screws. It has been reported that $95 \%$ of the Caucasian population, ${ }^{[16]}$ $67 \%$ of the Malaysian population, ${ }^{[17]} 65 \%$ of the Brazilian population $^{[14]}$ and $89.1 \%$ of the Greek population ${ }^{[19]}$ are suitable for two $3.5 \mathrm{~mm}$ screws. The minimum value of the OPmin we obtained in males was in the 18-30 year old group and was $7.8 \mathrm{~mm}$ in females; in the group over 50 , this was $6.9 \mathrm{~mm}$. This value was higher than the smallest value $(5.59 \mathrm{~mm})$ observed in the Malaysian and Caucasian populations, smaller than the smallest value $(9.10 \mathrm{~mm})$ measured in the Greek population. ${ }^{[16,17,20]}$ There are large differences in cortical thickness between populations and in some studies measurements were made on axial slices. ${ }^{[19,21]}$

Table 4

Average values of measurement parameters for females, males and total group.

\begin{tabular}{lccc}
\hline Measurement & $\begin{array}{c}\text { Females } \\
(\mathbf{n}=\mathbf{4 5})\end{array}$ & $\begin{array}{c}\text { Males } \\
(\mathbf{n}=\mathbf{5 5})\end{array}$ & $\begin{array}{c}\text { Total } \\
(\mathbf{n}=\mathbf{1 0 0})\end{array}$ \\
\hline OPmin $(\mathrm{mm})$ & 9.1 & 9.5 & 9.3 \\
OPmax $(\mathrm{mm})$ & 12 & 12.4 & 12.2 \\
OPAP $(\mathrm{mm})$ & 11.2 & 11.94 & 11.5 \\
OPL $(\mathrm{mm})$ & 14.7 & 15.9 & 15.3 \\
$\left.\operatorname{VOL}(\mathrm{mm})^{2}\right)$ & 11.9 & 13.9 & 13 \\
LAIT $(\mathrm{mm})$ & 36.5 & 38.9 & 37.5 \\
OPangle $\left(^{\circ}\right)$ & 12.6 & 11.8 & 12.14 \\
\hline
\end{tabular}




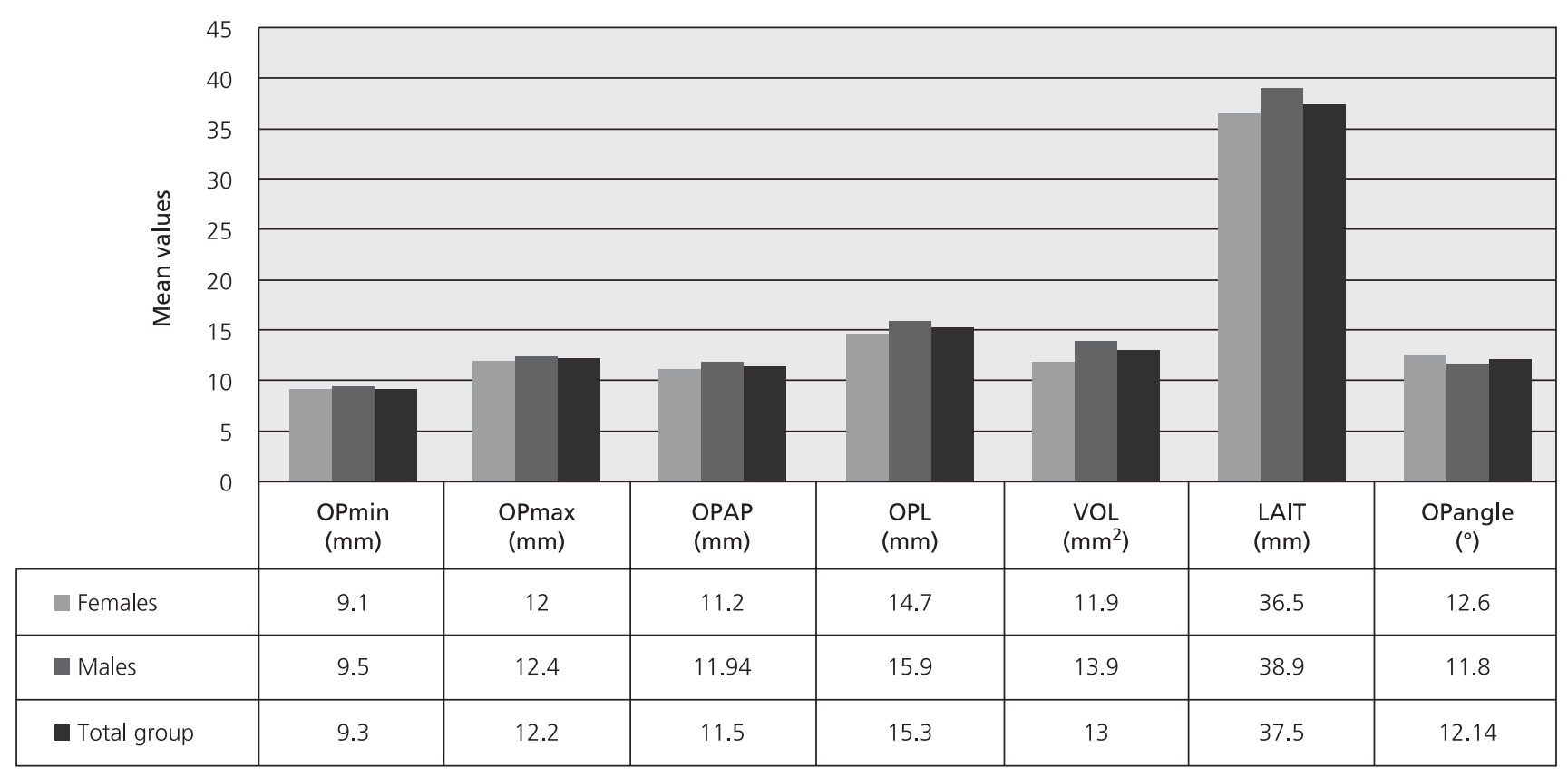

Figure 2. Graphic showing the changes in the mean values of the measurement parameters of the females, males and total groups.

In our study, the mean LAIT parameter was $38.9 \mathrm{~mm}$ $(30.5-45.8 \mathrm{~mm})$, higher in males than in females (Table 2). These results show similarities with the results of Korres et al. ${ }^{[19]}$ It has to be noted that the length of the screws used is different from the superoinferior length of the axis. This is because the screw entry point is not on the center of the vertebral body, but on the lower edge. In addition, the top end of the screw must not reach the end of the odontoid process. As a result, the applied screw should be $1-3 \mathrm{~mm}$ shorter than the LAIT. ${ }^{[21}$

In a study conducted on a Greek population, OPL was measured as $17.28 \mathrm{~mm}(13.24-22.91 \mathrm{~mm})$ in all groups, $17.66 \mathrm{~mm}(13.24-22.91 \mathrm{~mm})$ in males and 17.07 $\mathrm{mm}(14.11-21.44 \mathrm{~mm})$ in females. In our study, POU lengths were $15.3 \mathrm{~mm}$ in all groups (10.6 to $21.3 \mathrm{~mm}$ ), $15.9 \mathrm{~mm}(10.6$ to $21.3 \mathrm{~mm})$ in males and $14.7 \mathrm{~mm}(11.2$ $19.1 \mathrm{~mm}$ ) in females. Accordingly, OPL was lower in the Turkish population studied compared to the Greek. ${ }^{[19]}$

\section{Conclusion}

The results of this study showed that it is possible to use a single $4.5 \mathrm{~mm}$ or $3.5 \mathrm{~mm}$ cannulated screw in the Turkish population. The application of two $3.5 \mathrm{~mm}$ screws is appropriate in $76 \%$ of males and $62 \%$ of female populations. The results obtained from this study emphasize the importance of knowing the actual size of the odontoid process before the proper management of the anterior screwing technique in odontoid process fractures and it is believed that it provides reliable results based on the 3-dimensional reconstruction method.

\section{References}

1. Şahinoğlu K, transl. editor. Moore KL, Dalley AF, Agur AMR. Kliniğe yönelik anatomi. İstanbul: Nobel Tıp Kitabevleri; 2015. p. 1136.

2. Moore KL, Dalley II AF. Clinically oriented anatomy. 4th ed. Philadelphia (PA): Lippincott Williams and Wilkins; 1999. p. 1164.

3. Arıncı K, Elhan A. Anatomi. Ankara: Güneş Kitabevi; 2014. p. 856.

4. Holdsworth F. Fractures, dislocations, and fracture-dislocations of the spine. J Bone Joint Surg Am 1970;52:1534-51.

5. Standring S, editor. Gray's anatomy: the anatomical basis of clinical practice. 40th ed. Edinburgh: Elsevier Churchill Livingstone; 2008. p. 1576.

6. Gövsa Gökmen F. Sistematik anatomi. İzmir: Güven Kitabevi; 2008.

7. Cramer GD. The cervical region. In: Cramer GD, Darby SA, editors. Clinical anatomy of the spine, spinal cord, and ANS. 3rd ed. St. Louis (MO): Mosby; 2014. p. 135-209

8. Korres DS. Fractures of the odontoid process. In: Korres DS, editor. The axis vertebra. Berlin: Springer-Verlag; 2013. p. 45-59

9. Akobo S, Rizk E, Loukas M, Chapman JR, Oskouian RJ, Tubbs RS. The odontoid process: a comprehensive review of its anatomy, embryology, and variations. Childs Nerv Syst 2015;31:2025-34.

10. Böhler J. Anterior stabilization for acute fractures and non-unions of the dens. J Bone Joint Surg Am 1982;64:18-27. 
11. Bednar DA, Parikh J, Hummel J. Management of type II odontoid process fractures in geriatric patients; a prospective study of sequential cohorts with attention to survivorship. J Spinal Disord 1995;1669 .

12. Henry AD, Bohly J, Grosse A. Fixation of odontoid fractures by an anterior screw. J Bone Joint Surg Br 1999;81:472-7.

13. Cloché T, Vital JM. Chirurgie des traumatismes récents du rachis cervical. EMC - Techniques chirurgicales - Orthopedie-Traumatologie 2016;11:1-28 [Article 44-176].

14. Daher MT, Daher S, Nogueira-Barbosa MH, Defino HLA. Computed tomographic evaluation of odontoid process: implications for anterior screw fixation of odontoid fractures in an adult population. Eur Spine J 2011;20:1908-14.

15. Apfelbaum RI, Lonser RR, Veres R, Casey A. Direct anterior screw fixation for recent and remote odontoid fractures. J Neurosurg 2000;227-36.

16. Nucci RC, Seigal S, Merola AA, Gorup J, Mroczek KJ, Dryer J, Zipnick RI, Haher TR. Computed tomographic evaluation of the normal adult odontoid. Implications for internal fixation. Spine (Phila Pa 1976) 1995;20:264-70.
17. Yusof MI, Yusof AH, Abdullah MS, Hussin TM. Computed tomographic evaluation of the odontoid process for two-screw fixation in type-II fracture: a Malaysian perspective. J Orthop Surg (Hong Kong) 2007;15:67-72.

18. Schaffler MB, Alson MD, Heller JG, Garfin SR. Morphology of the dens. A quantitative study. Spine (Phila Pa 1976) 1992;17:738 43.

19. Korres DS, Lazaretos J, Papailiou J, Kyriakopoulos E, Chytas D, Efstathopoulos NE, Nikolaou VS. Morphometric analysis of the odontoid process: using computed tomography--in the Greek population. Eur J Orthop Surg Traumatol 2016;26:119-25.

20. Nakanishi T, Sasaki T, Takahata T, Aoki Y, Sueyasu MU, M, Washiya S IK. Internal fixation of odontoid process. Orthop Surg Traumatol 1980;23:399-406.

21. Doherty BJ, Heggeness MH, Esses SI. A biomechanical study of odontoid fractures and fracture fixation. Spine (Phila Pa 1976) 199318:178-84.

22. Tun K, Kaptanoglu E, Cemil B, Yorubulut M, Karahan ST, Tekdemir I. Anatomical study of axis for odontoid screw thickness, length, and angle. Eur Spine J 2009;8:271-5.

Correspondence to: Ece Alim, MD

E. Alim 0000-0002-4686-0677;

K. Atalar 0000-0003-1239-1144;

I. N. Gülekon 0000-0002-9352-5118

deomed.
Department of Anatomy, School of Medicine, Gazi University, Ankara, Turkey

Phone: +90 5419820606

e-mail: ece.alim06@gmail.com

Conflict of interest statement: No conflicts declared.

This is an open access article distributed under the terms of the Creative Commons Attribution-NonCommercial-NoDerivs 3.0 Unported (CC BY-NC-ND3.0) Licence (http://creativecommons.org/licenses/by-nc-nd/3.0/) which permits unrestricted noncommercial use, distribution, and reproduction in any medium, provided the original work is properly cited. Please cite this article as: Alim E, Atalar K, Gülekon IN. A morphometric study of the odontoid process using threedimensional computed tomography (3-D CT) reconstruction. Anatomy 2019;13(2):80-86. 